Acta Technologica Agriculturae 3

Nitra, Slovaca Universitas Agriculturae Nitriae, 2019, pp. 80-85

\title{
APPLICATION OF COMPUTATIONAL INTELLIGENCE METHODS FOR PREDICTING SOIL STRENGTH
}

\author{
Yousef ABBASPOUR-GILANDEH*, Mohammadreza ABBASPOUR-GILANDEH
}

University of Mohaghegh Ardabili, Ardabil, Iran

\begin{abstract}
The aim of this study was to make predictions for soil cone index using artificial neural networks (ANNs), adaptive neuro-fuzzy inference system (ANFIS) and a regression model. Field tests were conducted on three soil textures and obtained results were analyzed by application of a factorial experiment based on a Randomized Complete Block Design with five replications. The four independent variables of percentage of soil moisture content, soil bulk density, electrical conductivity and sampling depth were used to predict soil cone index by ANNs, ANFIS and a regression model. The ANNs design was that of back propagation multilayer networks. Predictions of soil cone index with ANFIS were made using the hybrid learning model. Comparison of results acquired from ANNs, ANFIS and regression models showed that the ANFIS model could predict soil cone index values more accurately than ANNs and regression models. Considering the ANFIS model, a novel result on soil compaction modeling, relative error $(\varepsilon)$, and regression coefficient $\left(R^{2}\right)$ were calculated at $2.54 \%$ and 0.979 , respectively.
\end{abstract}

Keywords: artificial neural network; ANFIS; cone index; modeling; Levenberg-Marquardt algorithm

Soil compaction is an index that displays the soil structure's physical deterioration and is defined as increased soil bulk density or reduced porosity. Certain methods, standards, and indices are used to determine the soil compaction, such as soil color index (compression recognition by means of observation), measurement of soil bulk density, penetrating the soil with radars and evaluation of the soil cone index (Hemmat et al., 2014; Raper et al., 1990; Upadhyaya et al., 1994). In terms of these methods, cone penetrometers were determined as the most reliable (Abbaspour-Gilandeh and Rahimi-Ajdadi, 2016; Clark, 1999; Mulqeen et al., 1977).

The advantage of using an artificial neural network is that it can create a connection between input and output parameters without any theory of predetermined mathematical relations (Goh, 1995; Kushwaha and Zhang, 1998; Levine et al., 1996). The reason for using ANNs and ANFIS for soil cone index predictions in this study is that they show high prediction capability and no mathematical relationship between dependent and independent variables.

Research has demonstrated a correlation between evaluations of the soil cone index and soil bulk density as parameters related to soil compaction and compression (Bayat et al., 2017; Henderson et al., 1988) and between the soil cone index and moisture content (Faure and Da Mata, 1994).

Abbaspour-Gilandeh et al. (2006) reported that soil electrical conductivity (EC) data were highly correlated to soil texture (\% clay content) with a correlation coefficient of 0.916 and that there was a strong linear correlation between soil EC and draft force across a field. The soil cone index could also be a function of soil electrical conductivity (Abbaspour-Gilandeh et al., 2011).

Santos et al. (2012) used statistical analyses and ANNs for predicting soil penetration resistance based on the soil bulk density and water content. Results showed that ANNs architecture 2-2-2-1 presented an RMSE (Root Mean Square Error) of value less than 0.085 , an $R^{2}$ equal to 0.98 and a global mean error of approximately $6.75 \%$, whereas the model obtained from statistical analyses presented an RMSE of 0.951 and an $R^{2}$ of 0.92 .

The aim of this study was to develop models based on computational intelligence methods and the regression method for predicting soil cone index. For the purposes of modeling of the soil cone index, artificial neural networks (ANNs), adaptive neuro-fuzzy inference system (ANFIS) and multiple range regression methods were utilized. Finally, performances of these models were compared with each other.

\section{Material and methods}

\section{Field experiments}

Field experiments were conducted at the Educational and Experimental Farm of the University of Mohaghegh Ardabili, Ardabil, Iran (latitude $38^{\circ} 19^{\prime} \mathrm{N}$, longitude $48^{\circ} 20^{\prime} \mathrm{E}$ ). Tests were done on three types of soil texture (loam, loamy sand and sandy loam). The effects of three soil moisture content levels (dry, semi-humid and humid), three sampling depths (0-10, 10-20 and 20-30 cm) and three numbers of tractor passes (0,10 and 20 passes) on soil cone index were

Contact address: Yousef Abbaspour-Gilandeh, University of Mohaghegh Ardabili, College of Agriculture and Natural Resources, Department of Biosystems Engineering, Ardabil, Iran, e-mail: abbaspour@uma.ac.ir 
investigated by application of a factorial experiment based on a Randomized Complete Block Design (RCBD) with five replications using MSTATC Version 2.0.0 statistical software. Considering each test plot, evaluations were made for soil cone index, percentage of soil moisture content, soil bulk density and soil electrical conductivity.

A tractor-mounted cone pernetrometer (Abbaspour-Gilandeh et al., 2010) was used to measure the strength of the soil. Calculations for cone index were based on measurements of the force required to press a cone with a $130 \mathrm{~mm}^{2}$ base area and $30^{\circ}$ point angle into the soil according to the ASAE standard S313.2.

Soil moisture content percentage was measured utilizing Eq. 1; soil samples were extracted from the given depths and subsequently weighed with a precise scale.

$$
M C=\left(\frac{W_{w}-W_{d}}{W_{d}}\right) \times 100
$$

where:

$$
W_{w} \quad \text { - weight of wet matter (g) }
$$$$
W_{d} \quad \text { - weight of dry matter (g) }
$$

To determine the soil bulk density, undistributed soil samples were taken from various depths in the range of 0-30 cm from the test field. Samples were oven dried at $105^{\circ} \mathrm{C}$ for 24 hours, weighed and measured for weight of dry soil and soil volume. Then, soil bulk density was determined by dividing the weight of sample by its volume.

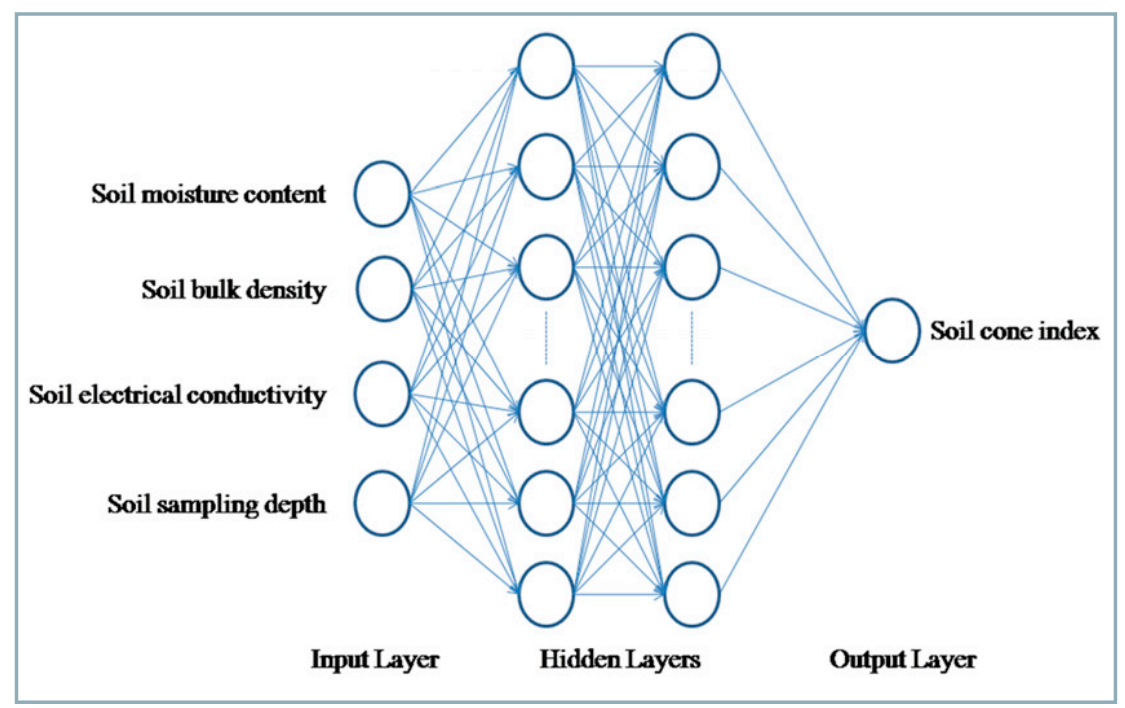

Fig. 1 Layers and connections of a feed-forward back propagating ANN
An electrical conductivity meter device was used to evaluate electrical conductivity. The electrical conductivity of a solution should be determined at the temperature of $25^{\circ} \mathrm{C}$. Eq. 2 was used to correct the values of soil electrical conductivity (Abbaspour-Gilandeh et al., 2011).

$$
E C_{25}=E C_{t}-0.02(t-25) E C_{t}
$$

where:

$$
\begin{array}{rrr}
E C_{25}- & \text { electrical conductivity of } \\
& \text { solution at } 25^{\circ} \mathrm{C}\left(\mu \mathrm{S} \cdot \mathrm{cm}^{-1}\right) \\
E C_{t}- & \text { measured electrical } \\
& \text { conductivity of solution at } \\
& \text { the actual temperature of the } \\
& \text { solution }\left(\mu \mathrm{S} \cdot \mathrm{cm}^{-1}\right) \\
t & - & \text { actual temperature of the } \\
& \text { solution }\left({ }^{\circ} \mathrm{C}\right)
\end{array}
$$

\section{Design of the Artificial Neural Networks (ANNs) model}

A multilayer back propagation network was used for making soil cone index predictions in the network designed in this research. Fig. 1 shows layers and connections of the designed feedforward back propagating artificial neural network. The three algorithms of descent gradient algorithm with momentum, Levenberg-Marquardt algorithm and scaled conjugated gradient algorithm were used to train the network with MATLAB version R2017a (Matlab, 1994).

Selecting the number of neurons in a middle layer is made by "trial and error". In this study, selection for the number of hidden layers and the number of neurons in the middle layers was made by comparing the performance among different networks. Moreover, the type of function used between input and middle layers was sigmoid tangent and linear was used between middle and output layers.

Data were divided into three subcategories including training, validation and testing in such a way that one fourth of data $(25 \%)$ were considered for testing, $25 \%$ for evaluation and half (50\%) for training. The best method of training for data and performance of the developed networks was determined by calculating the mean square error (MSE), sum of square errors (SSE), coefficient of determination $\left(R^{2}\right)$, and prediction accuracy (PA) (Gautam et al., 2003; Matlab, 1994).

\section{Design of adaptive neuro-fuzzy inference system (ANFIS)}

By combining the fuzzy inference system (FIS) with ANNs that is termed ANFIS, it is possible to acquire both the learning capabilities of a neural network and reasoning capabilities of fuzzy logic for predictions. The goal of ANFIS was to determine a model for correct associating of input values with the target. The ANFIS model proposed in this study was a multilayer neural network-based fuzzy system. Its topology is shown in Fig. 2 and the system had a total of five layers. The hidden layers consisted of nodes functioning as membership functions (MFs) and rules. In this model, to estimate soil cone index, $80 \%$ of total data was used for training and $20 \%$ of the data was used for validation. Triangular shaped membership functions were used as input variables because of their accuracy. The hybrid learning model was selected for soil cone index prediction with ANFIS.

Fig. 3 shows the data set used to train and check the soil cone index model with ANFIS. Training data were marked with the $(\bigcirc)$ sign and the check data were indicated with the plus sign (+) in Fig. 3. To initialize FIS using ANFIS, two partition methods were used - grid partitioning and subtractive clustering. The main difference between these two methods is related to how the fuzzy 


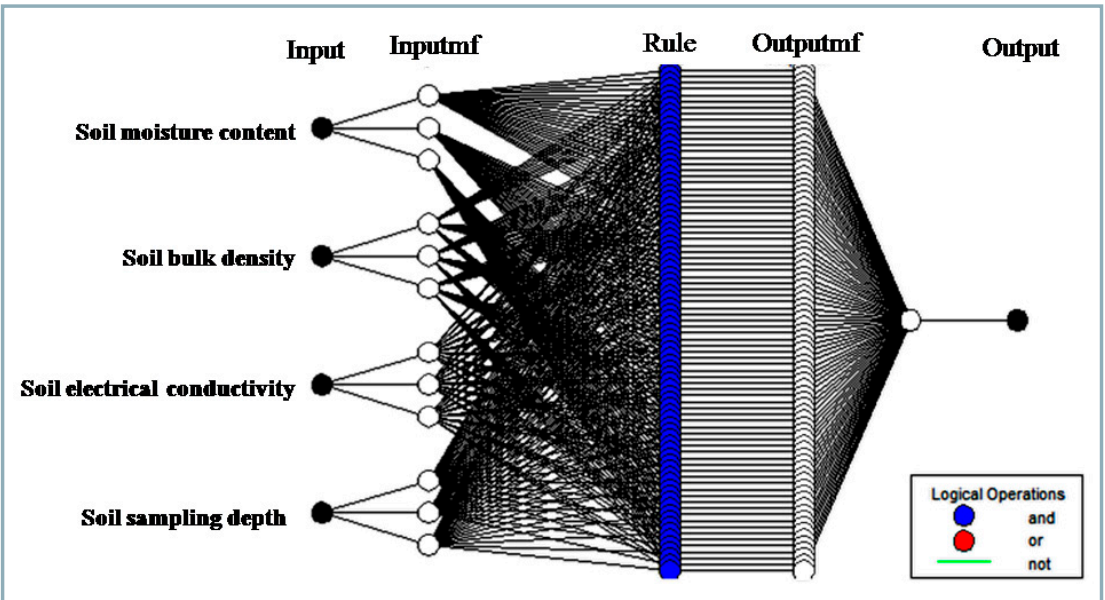

Fig. 2 ANFIS architecture for soil cone index prediction

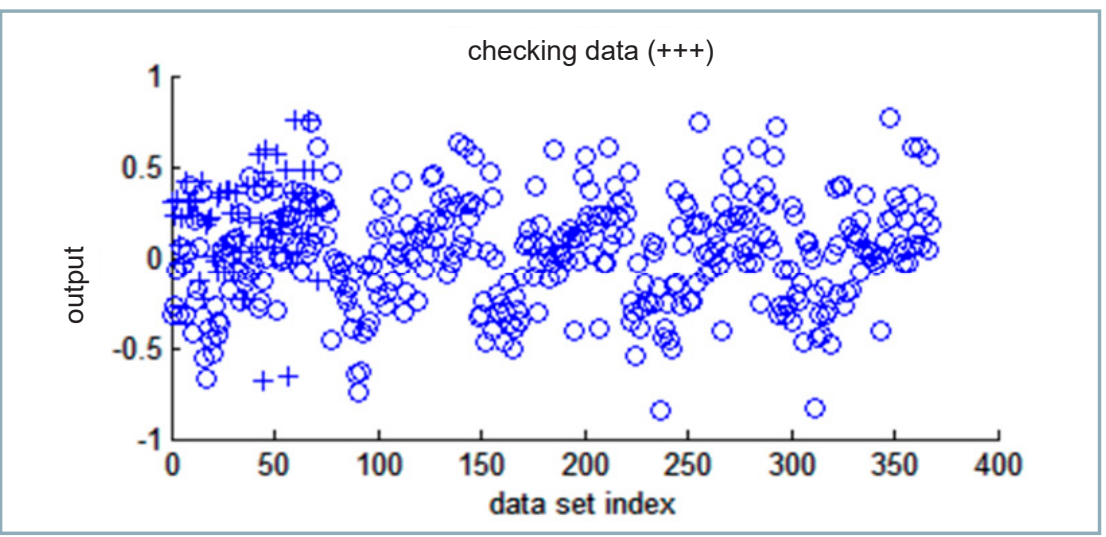

Fig. 3 Loading training and checking data in ANFIS

Table 1 The results of analysis of variance of soil cone index

\begin{tabular}{|l||c|c|}
\hline Variation source & Degree of freedom & Mean square \\
\hline Replication & 4 & $15,949.515^{\text {ns }}$ \\
\hline Soil texture & 2 & $6,125,782.724^{* *}$ \\
\hline Moisture content & 2 & $430,853.772^{* *}$ \\
\hline Texture $\times$ moisture & 4 & $555,545.556^{* *}$ \\
\hline Tractor traffic & 2 & $1,823,290.459^{* *}$ \\
\hline Texture $\times$ tractor traffic & 4 & $32,189.957^{\text {ns }}$ \\
\hline Moisture $\times$ traffic & 4 & $43,466.475^{*}$ \\
\hline Texture $\times$ moisture $\times$ traffic & 8 & $107,463.83^{* *}$ \\
\hline Depth & 2 & $6,029,325.987^{* *}$ \\
\hline Texture $\times$ depth & 4 & $135,206.146^{* *}$ \\
\hline Moisture $\times$ depth & 4 & $57,439.856^{* *}$ \\
\hline Texture $\times$ moisture $\times$ depth & 8 & $50,648.257^{* *}$ \\
\hline Traffic $\times$ depth & 4 & $121,767.287^{* *}$ \\
\hline Texture $\times$ traffic $\times$ depth & 8 & $161,720.162^{* *}$ \\
\hline Moisture $\times$ traffic $\times$ depth & 8 & $58,766.067^{* *}$ \\
\hline Texture $\times$ moisture $\times$ traffic $\times$ depth & 16 & $79,912.831^{* *}$ \\
\hline Error & 320 & $14,879.165$ \\
\hline Total & 404 & - \\
\hline$* *{ }^{*}$ significant at probability levels of $\%$ and $5 \%$, respectively and ${ }^{n s}:$ no significant \\
\hline
\end{tabular}

membership function is selected. Considering the grid partitioning method, type and number of the input membership function vector was determined by the user.

\section{Results and discussion}

\section{Analysis of variance of data}

Results of Analysis of Variance for the soil cone index are given in Table 1 . Results of ANOVA show that the main effects of soil texture, tractor traffic and sampling depth individually had significant impact on soil cone index $(P<0.01)$. Furthermore, interaction effects of moisture content and tractor traffic on soil cone index was significant $(P<0.05)$. However, the interaction effect of soil texture and tractor traffic on soil cone index was determined as not significant. This shows that effects of these two factors on soil cone index were independent of each other. The results of this section indicate that effects of the four parameters - soil texture, moisture content, tractor traffic and sampling depth - should be considered in modeling soil cone index (Varga et al., 2013).

\section{Presenting a regression model for soil cone index}

To determine the mathematical model of soil cone index as a dependent variable in relation to the percentage of soil moisture content, data from soil bulk density, electrical conductivity and sampling depth were used as independent variables (Bayat et al., 2017). The multiple-regression model was used for statistical operations. Linear model used as a mathematical model of soil cone index is shown in Eq. 3:

$$
\begin{gathered}
C l=26.2(S D)+1,298.6(B D)- \\
-28.8(M C)+133.3(\log E C)-1,026.6
\end{gathered}
$$

where:

$\mathrm{Cl}$ - cone index $(\mathrm{kPa})$

$S D$ - sampling depth $(\mathrm{cm})$

$B D$ - bulk density $\left(\mathrm{g} \cdot \mathrm{cm}^{-3}\right)$

EC - electrical conductivity $\left(\mu \mathrm{S} \cdot \mathrm{cm}^{-1}\right)$

\section{Soil cone index prediction using artificial neural network}

Table 2 shows results from the designed neural networks for soil cone 
Table 2 Quantitative evaluation standards of made networks by using the Levenberg-Marquardt training algorithm

\begin{tabular}{|l||c|c|c|c|c|c|c|c|c|c|}
\hline \multirow{2}{*}{$\begin{array}{l}\text { The } \\
\text { number of } \\
\text { neurons }\end{array}$} & \multicolumn{2}{|c|}{ Network parameters } & \multicolumn{2}{c|}{$\begin{array}{c}\text { Network statistical } \\
\text { parameters }\end{array}$} & \multicolumn{2}{|c|}{$\begin{array}{c}\text { Network's determination } \\
\text { coefficients }\end{array}$} & \multicolumn{2}{|c|}{$\begin{array}{c}\text { The mean } \\
\text { simulation } \\
\text { accuracy test (\%) }\end{array}$} & $\begin{array}{l}\text { Correlation } \\
\text { coefficient }\end{array}$ \\
\cline { 2 - 13 } & learning rater & momentum & MSE & SSE & training & validation & test & \\
\hline \hline $\mathbf{2 8 - 3 0}$ & 0.3 & 0.3 & 0.072 & 16.2 & 0.96 & 0.76 & 0.83 & 87.98 & 0.88 \\
\hline $\mathbf{3 0 - 3 0}$ & 0.3 & 0.3 & 0.0669 & 15.1 & 0.97 & 0.68 & 0.84 & 88.04 & 0.89 \\
\hline $\mathbf{3 0 - 3 2}$ & 0.3 & 0.3 & 0.119 & 26.7 & 0.91 & 0.83 & 0.85 & 88.09 & 0.87 \\
\hline $\mathbf{3 2 - 3 2}$ & 0.3 & 0.3 & 0.0741 & 16.7 & 0.94 & 0.82 & 0.83 & 87.76 & 0.87 \\
\hline $\mathbf{3 2 - 3 4}$ & 0.3 & 0.3 & 0.0895 & 20.1 & 0.95 & 0.74 & 0.86 & 88.78 & 0.88 \\
\hline $\mathbf{3 4 - 3 4}$ & 0.3 & 0.3 & 0.0875 & 19.7 & 0.95 & 0.83 & 0.85 & 88.29 & 0.89 \\
\hline
\end{tabular}

Table 3 Designed networks utilizing 3 training algorithms each having the optimized number of neurons in their hidden layer (layers)

\begin{tabular}{|c|c|c|c|c|c|c|c|c|}
\hline \multirow[t]{2}{*}{$\begin{array}{l}\text { Training } \\
\text { algorithm }\end{array}$} & \multirow[t]{2}{*}{$\begin{array}{l}\text { Transfer } \\
\text { function }\end{array}$} & \multirow{2}{*}{$\begin{array}{c}\text { The } \\
\text { optimized } \\
\text { structure of } \\
\text { network }\end{array}$} & \multirow[t]{2}{*}{$\begin{array}{l}\text { Mean } \\
\text { squares }\end{array}$} & \multicolumn{3}{|c|}{$\begin{array}{l}\text { Determination coefficients of the } \\
\text { network }\end{array}$} & \multirow{2}{*}{$\begin{array}{l}\text { The mean } \\
\text { simulation } \\
\text { accuracy of the } \\
\text { network (\%) }\end{array}$} & \multirow[t]{2}{*}{$\begin{array}{l}\text { Correlation } \\
\text { coefficient }\end{array}$} \\
\hline & & & & training & evaluation & test & & \\
\hline \multirow{4}{*}{$\begin{array}{l}\text { Scaled } \\
\text { conjugate } \\
\text { gradient }\end{array}$} & \multirow{2}{*}{ Sig tan } & $20+1$ & 0.131 & 0.87 & 0.86 & 0.86 & 88.97 & 0.86 \\
\hline & & $12+12+1$ & 0.128 & 0.88 & 0.86 & 0.85 & 87.77 & 0.86 \\
\hline & \multirow{2}{*}{ Sig log } & $13+1$ & 0.137 & 0.86 & 0.87 & 0.86 & 88.71 & 0.86 \\
\hline & & $12+12+1$ & 0.13 & 0.87 & 0.86 & 0.85 & 87.97 & 0.86 \\
\hline \multirow{4}{*}{$\begin{array}{l}\text { Descent } \\
\text { gradient } \\
\text { with } \\
\text { momentum }\end{array}$} & \multirow{2}{*}{ Sig tan } & $6+1$ & 0.141 & 0.86 & 0.85 & 0.85 & 88.07 & 0.85 \\
\hline & & $6+6+1$ & 0.14 & 0.85 & 0.85 & 0.84 & 87.44 & 0.85 \\
\hline & \multirow{2}{*}{ Sig log } & $12+1$ & 0.126 & 0.87 & 0.86 & 0.85 & 87.78 & 0.86 \\
\hline & & $6+6+1$ & 0.116 & 0.88 & 0.87 & 0.86 & 88.37 & 0.87 \\
\hline \multirow{4}{*}{$\begin{array}{l}\text { Levenberg- } \\
\text { Marquardt }\end{array}$} & \multirow{2}{*}{ Sig tan } & $25+1$ & 0.0974 & 0.92 & 0.85 & 0.85 & 87.98 & 0.87 \\
\hline & & $12+13+1$ & 0.0981 & 0.93 & 0.85 & 0.87 & 88.81 & 0.88 \\
\hline & \multirow{2}{*}{ Sig log } & $24+1$ & 0.102 & 0.94 & 0.82 & 0.87 & 86.48 & 0.88 \\
\hline & & $34+34+1$ & 0.0875 & 0.95 & 0.83 & 0.86 & 88.29 & 0.89 \\
\hline
\end{tabular}

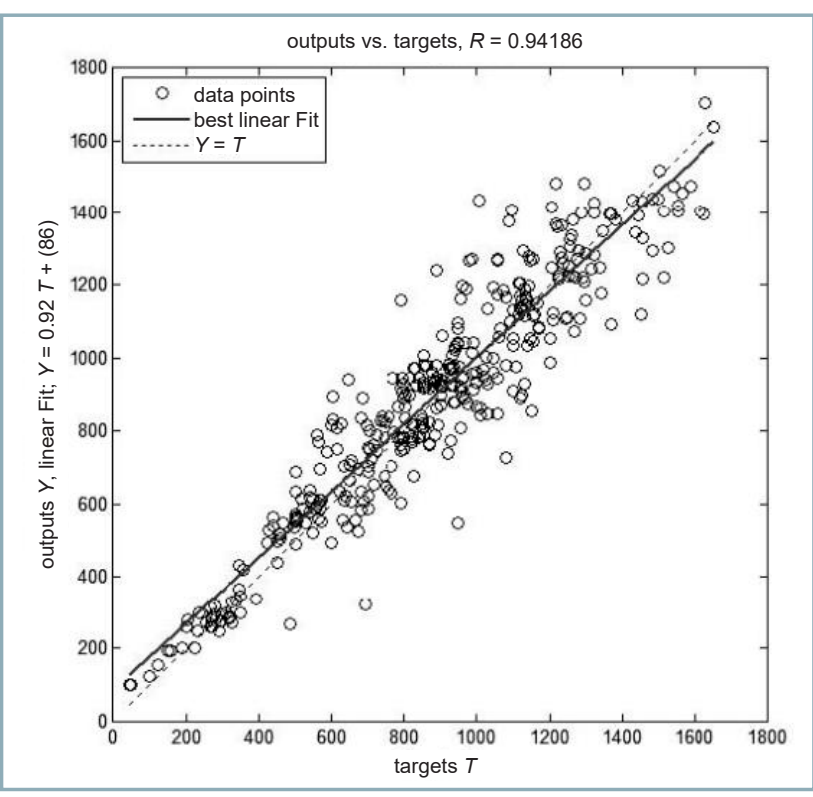

Fig. 4 The regression chart for evaluation step of the network to predict the soil cone index quantities index prediction using the Levenberg-Marquardt algorithm with a middle layer (middle layers) and a different number of neurons in the middle layer (layers). The sigmoid tangent function was used between the input and middle layers and a linear type was used between the middle layers and the output layer. As shown in Table 2, the network containing 34 neurons in each middle layer for predicting the soil cone index quantities had the lowest value for mean square error, the least sum of squares error, the highest correlation coefficient, the maximum simulation accuracy and the highest determination coefficient. Therefore, this topology was selected for the network design.

A diagram indicating the best fitted line between real data $(T)$ and predicted data by the network $(Y)$ is shown in Fig. 4. The regression coefficients for soil cone index prediction between the data groups were extracted by as much as 0.94 for the built network with 34 neurons in each middle layer for predicting soil cone index quantities. The highest gradient and the maximum correlation coefficient were extracted for this structure. These quantities for prediction of the soil cone index were 0.9195 and 0.9419 , respectively. 
Table 4 Characteristics of ANFIS model and its evaluation based on statistical parameters

\begin{tabular}{|c|c|c|c|c|c|c|c|}
\hline \multicolumn{2}{|c|}{ Type of membership functions } & \multicolumn{2}{|c|}{ Number of membership functions } & \multirow{2}{*}{$\begin{array}{l}\text { Learning } \\
\text { method }\end{array}$} & \multirow{2}{*}{ RMSE } & \multirow{2}{*}{$\varepsilon(\%)$} & \multirow{2}{*}{$R^{2}$} \\
\hline input & output & input & epoch & & & & \\
\hline triangular & linear & 5 & 30 & hybrid & 0.621 & 2.54 & 0.979 \\
\hline
\end{tabular}

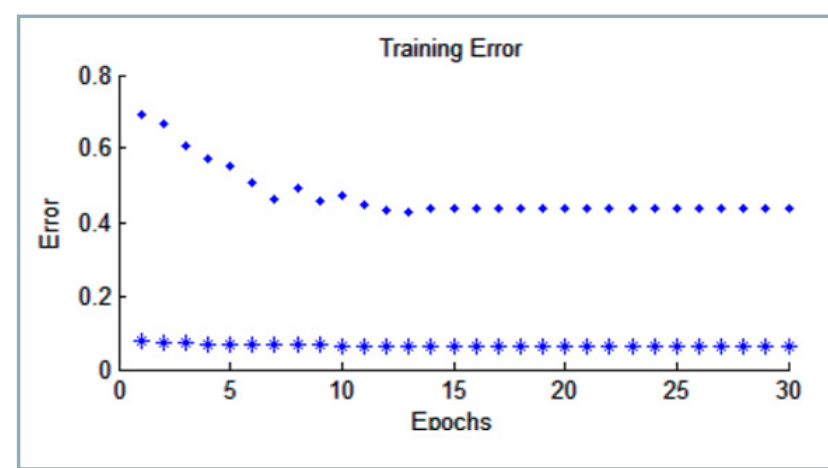

Fig. 5 Changes in the training and checking data error

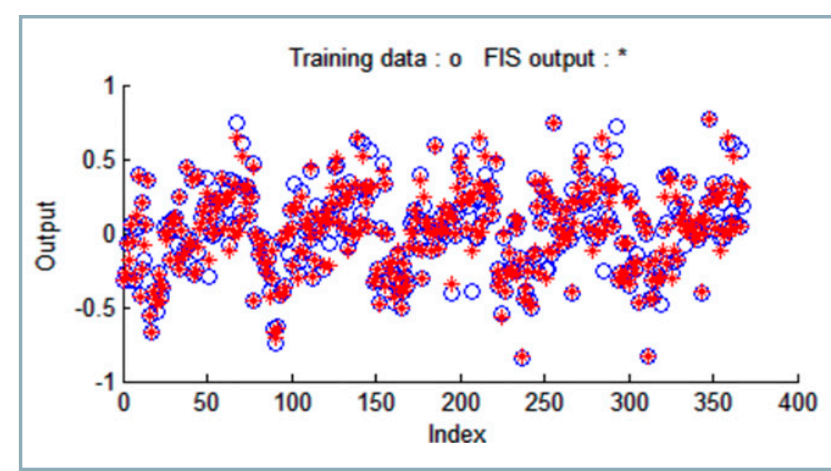

Fig. 6 Comparison of predicted data with training data

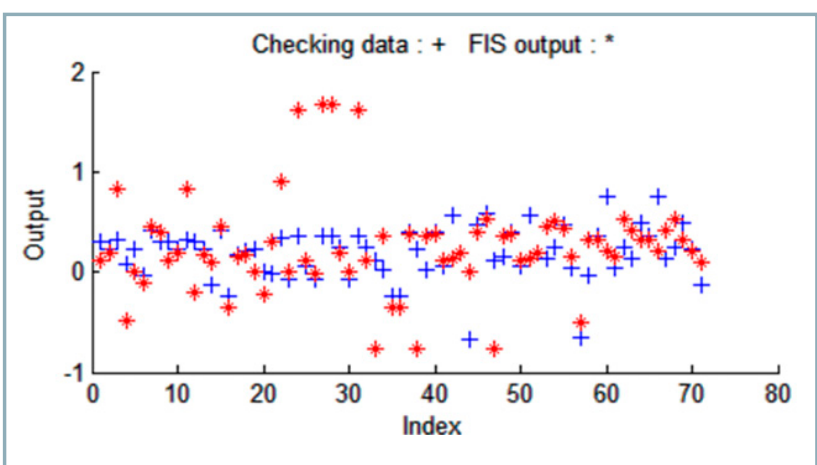

Fig. 7 Comparison of predicted data with checking data

Table 3 shows a summary of the results of built networks utilizing the 3 aforementioned training algorithms and a comparison of their statistical parameters and accuracy. As shown in Table 3, Levenberg-Marquardt training algorithm presented better results in simulation and training of the artificial neural network compared with the other training algorithms. The Levenberg-Marquardt training algorithm associated to sigmoid logarithm transfer function containing 2 hidden layers and 34 neurons in each hidden layer had a lower mean square and higher determination of coefficients in training, validation and test steps of the network in comparison to the similar single-layer network.

\section{Prediction of soil cone index using ANFIS}

Fig. 5 shows the relationship between the root mean square error (RMSE) and epochs for training and checking data. Training data error and checking data error are marked with $\left(^{*}\right)$ and $(\star)$, respectively. Fig. 5 shows how the training and checking error decreased to a certain point. After training and checking the ANFIS model, predicted values of model were obtained and compared with the training and checking data. Results are shown in Figs. 6 and 7. Root Mean Square Errors were obtained at 0.621 and 0.436 for training and checking, respectively.

Table 4 shows characteristics of the model and its evaluations based on statistical parameters of RMSE, percentage of relative error $(\varepsilon)$ and coefficient of determination $\left(R^{2}\right)$. These results show that the ANFIS model was capable of estimating and predicting soil cone index with high accuracy.

\section{Conclusion}

The Analysis of Variance of soil cone index revealed that effects of the four parameters of soil texture, soil moisture content, tractor traffic and sampling depth were significant on soil cone index and should be taken into account in soil cone index modeling using artificial neural networks or a multiple-regression modeling (Ozoemena et al., 2018; Varga et al., 2013). The developed multiple-regression model was evaluated by normality assumption, assumption of constant variance and the Leverage index. Acceptable results were obtained from the multiple regression models to predict soil cone index values. The effects of independent variables had significant impact on soil cone index as a dependent variable $(P<0.01)$. Multilayer network back propagation with Levenberg-Marquardt algorithm showed better results in comparison to other algorithms utilized in data simulation and training of artificial neural networks. In terms of ANFIS model for the soil cone index estimation, novel result on soil cone index modeling, relative error $(\varepsilon)$, and regression coefficient $\left(R^{2}\right)$ were calculated at $2.54 \%$ and 0.979 , respectively. Comparison of the results achieved by ANFIS model with ANNs and regression models showed that ANFIS managed to model the soil cone index with high accuracy (Abbaspour-Gilandeh and Abbaspour-Gilandeh, 2019).

\section{References}

ABBASPOUR-GILANDEH, Y. - ABBASPOUR-GILANDEH, M. 2019. Modelling soil compaction of agricultural soils using fuzzy logic approach and adaptive neuro-fuzzy inference system (ANFIS) approaches. In Modeling Earth Systems and Environment, vol. 5, no. 1, pp. 13-20. 
ABBASPOUR-GILANDEH, Y. - ALIMARDANI, R. - KHALILIAN, A. KEYHANI, A. R. - SADATI, S. H. 2006. Energy requirement of sitespecific and conventional tillage as affected by tractor speed and soil parameters. In International Journal of Agriculture and Biology, vol. 8, no. 4, pp. 499-503.

ABBASPOUR-GILANDEH, Y. - AHANI, M. - ASKARI ASLI ARDEH, E. RASOOLI-SHARABIANI, V. - SOFALIAN, O. 2010. Design, construction and evaluation of a tractor-mounted soil cone penetrometer with multiple-adjustable-probes. In Iranian Journal of Agricultural Engineering Research, vol. 11, no. 1, pp. 19-34.

ABBASPOUR-GILANDEH, Y. - KHALILIAN, A. - HASANKHANI, F. 2011. Use of soil EC data for zoning the production field by artificial neural network for applying the precision tillage. In Journal of Agricultural Machinery Science, vol. 7, no. 1, pp. 27-31.

ABBASPOUR-GILANDEH, Y. - RAHIMI-AJDADI, F. 2016. Design, construction and field evaluation of a multiple blade soil mechanical resistance sensor. In Soil and Tillage Research, vol. 157, pp. 93-100. ASAE Standard S313.2: 1998. Soil cone penetrometer, $45^{\text {th }}$ ed. St. Joseph, Mich.: ASAE.

BAYAT, H. - SHEKLABADI, M. - MORADHASELI, M. - EBRAHIMI, E. 2017. Effects of slope aspect, grazing, and sampling position on the soil penetration resistance curve. In Geoderma, vol. 303, pp. 150-164.

CLARK, R. L. 1999. Evaluation of the potential to develop soil strength maps using a cone penetrometer. ASAE paper No. 99 3109, ASAE, St. Joseph, Mich. 49085, USA.

FAURE, A. G. - DA MATA, J. D. V. 1994. Penetration resistance value along compaction curves. In Journal of Geotechnical Engineering, vol. 120, pp. 46-59.

GAUTAM, R. K. - PANIGRAHI, S. - FRANZEN, D. 2003. Neural network models for soil nitrate prediction using imagery and non-imagery information. ASAE Paper No. 033065, ASAE, St. Joseph, MI.

$\mathrm{GOH}$, A. 1995. Back-propagation neural network for modeling complex systems. In Artificial Intelligence in Engineering, vol. 9, pp. 143-151.

HEMMAT, A. - RAHNAMA, T. - VAHABI, Z. 2014. A horizontal multiple-tip penetrometer for on-the-go soil mechanical resistance and acoustic failure mode detection. In Soil and Tillage Research, vol. 138, pp. 17-25.
HENDERSON, C. - LEVETT, A. - LISLE, D. 1988. The effect of soil water content and bulk density on the compactability and soil penetration resistance of some Western Australian sandy soils. In Australian Journal of Soil Research, vol. 26, pp. 391-400.

KUSHWAHA, R. - ZHANG, Z. X. 1998. Evaluation of factors and current approaches related to computerized design of tillage tools: a review. In Journal of Terramechanics, vol. 35, pp. 69-86.

LEVINE, E. R. - KIMES, D. S. - SIGILLITO, V. G. 1996. Classifying soil structure using neural networks. In Journal of Ecological Modelling, vol. 92, pp. 101-108.

MATLAB. 1994. Neural Network TOOLBOX. Natick, MA: The Mathworks Inc.

MULQEEN, J. - STAFFORD, J. V. - TANNER, D. W. 1977. Evaluation of penetrometers for measuring soil strength. In Journal of Terramechanics, vol. 14, no. 3, pp. 137-151.

OZOEMENA, A. A. - UZOEJINWA, B. B. - EZEAMA, A. O. - ONWUALU, A. P. - UGWU, S. N. - OHAGWU, C. J. 2018. Overview of soil-machine interaction studies in soil bins. In Soil and Tillage Research, vol. 175, pp. 13-27.

RAPER, R. L. - ASMUSSEN, L. E. - POWELL, J. B. 1990. Sensing hard pan depth with ground-penetrating radar. Transactions of the ASAE, vol. 33, no. 1, pp. 41-46.

SANTOS, F. L. - MENDES DE JESUS, V. A. - VALENTE, D. S. M. 2012. Modeling of soil penetration resistance using statistical analyses and artificial neural networks. In Acta Scientiarum: Agronomy, vol. 34, no. 2, pp. 219-224.

UPADHYAYA, S. K. - CHANCELLOR, W. J. - PERUMRAL, J.V. - SCHAFER, R. L. - GILL, W. R. - VANDENBERG, G. E. 1994. In Advances in Soil Dynamics (Vol. 1). American Society of Agricultural Engineers.

VARGA, F. - MOJŽIŠ, M. - ABRAHÁM, R. 2013. Soil resistance and its impact on tillage depth. In Acta Technologica Agriculturae, vol. 16, no. 1, pp. 26-30. 